\title{
The effect of antiseptic solution in central venous catheter care
}

\author{
Atahan K, Cokmez A, Bekoglu M, Durak E, Tavusbay C, Tarcan E \\ 1st Surgical Department, Atatürk Educational and Research Hospital, Izmir, Turkey. \\ kemalatahan@yahoo.com.tr
}

\begin{abstract}
Aim: Intravenous catheters have become one of the essential tools of modern medicine. Preventive measures taken while the catheter is being inserted or in place can provide a significant reduction in catheterrelated infections and bacteremia/sepsis.

This study aims to evaluate whether the patient's age and gender, the presence of malignancy and coexisting diseases, catheter duration, use of total parenteral nutrition solution, blood products, and antibiotics as well as antiseptics applied while attaching the central venous catheter (chlorhexidine and povidone-iodine) affect the development of catheter colonization and catheter-related bloodstream infections in patients with central venous catheters. Materials and methods: Our study includes 50 cases which were admitted to İzmir Atatürk Training and Research Hospital, I. Surgical Clinic, hospitalized due to various reasons between the dates of January-December 2010 and required catheter use. Patients were randomly assigned to one of the two operating rooms, in one of which the insertion site was disinfected with Poviiodeks ${ }^{\circledR}(10 \%$ povidone-iodine) while in the other, (latter) Savlosol $₫$ (15\% cetrimide, $1.5 \%$ Chlorhexidine-gluconate, ethanol) was used.

Results: Among many factors examined in our study, only the use of clorhexidine versus iodine povidon in skin antisepsis was found to be statistically significant in the reduction of CRBSI and CC (for CRBSI $p=0.022$ and for CC $p=0.047$ ). Conclusions: Our study concludes that skin antisepsis is the only determining factor in the prevention of blood infection and colonization due to central venous catheter application and the use of clorhexidine vs. povidon is proven to be statistically significant (Tab. 1, Ref. 27). Full Text in PDF www.elis.sk.

Key words: central venous catheter, chlohexidine, povidone-iodine, catheter colonization, catheter related blood infections.
\end{abstract}

Intravenous catheters have become one of the essential tools of modern medicine. The use of catheters has become an essential technique for fluid therapy, parenteral nutrition, close monitoring, application of blood and blood products, infusion of drugs as well as for other various invasive administrations. The infection caused by this widespread application has become an important issue in all aspects $(1-3)$. The importance of preventive measures is clear given the fact that the treatment of infections due to this widely used application is rather complicated $(4,5)$. The preventive measures taken while the catheter is being inserted or in place can provide a significant reduction in catheter-related infections and bacteremia/sepsis $(6,7)$.

This study aims to evaluate whether the patient's age and gender, the presence of malignancy and coexisting diseases, catheter duration, use of total parenteral nutrition (TPN) solution, blood products, and antibiotics, as well as antiseptics applied while attaching the central venous catheter (chlorhexidine and povidoneiodine) affect the development of catheter colonization (CC) and catheter-related bloodstream infections (CRBSI) in patients with central venous catheters (CVCs).

1st Surgical Department, Atatürk Educational and Research Hospital, Izmir, Turkey

Address for correspondence: K. Atahan, 6342 sok. No: 44 Ayse Kaya 2 apt., Kat: 3 Daire: 6, 35540 Bostanli, Izmir, Turkey.

Phone: +90.532 .4126805$

\section{Materials and methods}

This prospective study included a total of 50 patients who were hospitalized and catheterized for various reasons from January to December of 2010 at the Ataturk Educational and Research Hospital's First Surgical Clinic Service. Patients were randomly assigned to two operating rooms, in one of which the insertion site was disinfected with Poviiodeks $\AA$ (10\% povidone-iodine) while in the other, Savlosol ${ }^{\circledR}(15 \%$ cetrimide, $1.5 \%$ Chlorhexidinegluconate, ethanol) was used.

Non-tunneled radiopaque polyurethane double- and triplelumen catheters (Arrow International, Inc. USA) were used. All catheters were sterilized and then inserted percutaneously using the Seldinger technique by an experienced anesthesiologist and surgeon. Before inserting the catheter, the insertion site was disinfected with Poviiodeks ${ }^{\circledR}(10 \%$ povidone-iodine $)$ or Savlosol $\AA$ (15\% cetrimide, $1.5 \%$ Chlorhexidine-gluconate, ethanol) and covered with sterile gauze. The dressings were changed every 48 to 72 hours or earlier if necessary. The percutaneous insertion sites were checked every 24 hours for signs of local infection. The catheter was removed in cases that it was no longer needed, catheterrelated infection was suspected, infection developed from another source, or due to signs of entry-site erythema, induration, or local infection such as increased temperature or catheter obstruction. Before removing the catheter, its entry point and the surrounding area were disinfected. After withdrawal, the catheter's 5-cm tip 
Tab. 1. The results of compared groups.

\begin{tabular}{|c|c|c|c|c|c|c|}
\hline \multirow{3}{*}{ Age $? 45$} & \multicolumn{3}{|c|}{ Catheter-Related Bloodstream Infection } & \multicolumn{3}{|c|}{ Catheter Colonization } \\
\hline & \multicolumn{2}{|c|}{ resent (n/\%)Present (n/\%) } & \multirow[t]{2}{*}{$p$ value } & \multicolumn{2}{|c|}{ Not Present (n/\%)Present (n/\%) } & \multirow{3}{*}{$\begin{array}{r}p \text { value } \\
0,891 \\
\end{array}$} \\
\hline & $13 / 92,9$ & $1 / 7,1$ & & $10 / 71,4$ & $4 / 28,6$ & \\
\hline Age $>45$ & $33 / 91,7$ & $3 / 8,3$ & 0,889 & $25 / 69,4$ & $11 / 30,6$ & \\
\hline Male & $32 / 94,1$ & $2 / 5,9$ & & $21 / 61,8$ & $13 / 38,2$ & \\
\hline Female & $14 / 87,5$ & $2 / 12,5$ & 0,421 & $14 / 87,5$ & $2 / 12,5$ & 0,064 \\
\hline Malignancy - & $19 / 41,3$ & 0 & & $12 / 34,3$ & $7 / 46,7$ & \\
\hline Malignancy $(+)$ & $27 / 58,7$ & $4 / 100$ & 0,103 & $23 / 65,7$ & $8 / 53,3$ & 0,409 \\
\hline Comorbidity (-) & $29 / 63$ & $2 / 50$ & & $20 / 57,1$ & $11 / 73,3$ & \\
\hline Comorbidity $(+)$ & $17 / 37$ & $2 / 50$ & 0,606 & $15 / 42,9$ & $4 / 26,7$ & 0,28 \\
\hline 1 & $12 / 26,1$ & $2 / 28,0$ & & $11 / 31,4$ & $3 / 20,0$ & \\
\hline$>1$ & $5 / 10,9$ & $0 / 0,0$ & 0,525 & $4 / 11,4$ & $1 / 6,7$ & 0,557 \\
\hline Duration of catheter $<7$ days & $21 / 45,7$ & $2 / 50,0$ & & $18 / 51,4$ & $5 / 33,3$ & \\
\hline Duration of cathete days & $25 / 54,3$ & $2 / 50,0$ & 0,867 & $17 / 48,6$ & $10 / 66,7$ & 0,239 \\
\hline TPN used & $16 / 34,8$ & $2 / 50,0$ & & $11 / 31,4$ & $7 / 46,7$ & \\
\hline TPN not used & $30 / 65,2$ & $2 / 50,0$ & 0,543 & $24 / 68,6$ & $8 / 53,3$ & 0,304 \\
\hline Blood Product used & $21 / 45,7$ & $3 / 75,0$ & & $15 / 42,9$ & $9 / 60,0$ & \\
\hline Blood Product not used & $25 / 54,3$ & $1 / 25,0$ & 0,26 & $20 / 57,1$ & $6 / 40,0$ & 0,266 \\
\hline Antibiotics (combination) & $22 / 47,8$ & $11 / 25,0$ & & $15 / 42,9$ & $8 / 53,3$ & \\
\hline Antibiotics (mono) & $22 / 47,8$ & $3 / 75,0$ & & $18 / 51,4$ & $7 / 46,7$ & \\
\hline Antibiotics (not used) & $2 / 4,3$ & $0 / 0,0$ & 0,567 & $2 / 5,7$ & $0 / 0,0$ & 0,561 \\
\hline Chlorhexidine-based solution & $23 / 50,0$ & $0 / 0,0$ & & $17 / 48,6$ & $6 / 40,0$ & \\
\hline Alcohol-based Povidone Iodine & $23 / 50,0$ & $4 / 100,0$ & $0,022^{*}$ & $18 / 51,4$ & $9 / 60,0$ & $0,047^{*}$ \\
\hline
\end{tabular}

${ }^{*} \mathrm{p}<0,05$ statistically significant

TPN - Total Parenteral Nutrition

was broken aseptically and sent in a closed dry sterile tube to a microbiology laboratory. A swab of the catheter entry point and a peripheral blood sample were also taken under aseptic conditions. The swab sample was placed in a sterile tube while the peripheral blood sample was placed in Bacter-brand aerobic and anaerobic culture vials. The samples were subjected to a semi-quantitative culture procedure in a microbiology laboratory.

The following factors that might influence catheter-related bloodstream infections (CRBSI) and catheter colonization (CC) were recorded: patient's age and gender, presence of malignancy, presence of a coexisting disease and the number of coexisting diseases, catheter duration, use of TPN solution, use of blood products, use of single or multiple antibiotics and its duration, and whether $10 \%$ povidone-iodine or $1.5 \%$ chlorhexidine was used when inserting the catheter.

CRBSI was defined as a positive culture from peripheral venous blood and signs of systemic infection with microorganism identical to that cultured from the catheter.

$\mathrm{CC}$ was defined as a positive semiquantitative culture from the catheter (the tip, subcutaneous segment, and connector hub of the catheter) but without signs of infection at the catheter entry site. The results from the cultures were recorded.

All patients signed a consent form for this institutional review board (IRB)-approved study. The consent of subjects and that of
Ethics Board of İzmir Atatürk Training and Research Hospital were obtained before the study.

The correlations between the determining factors and CRBSI and $\mathrm{CC}$ were evaluated using the chi-square statistical analysis method. Mean $\pm S D$ values are summarized in the figures and tables. All of the analyses were done with the statistical software package SPSS 15.0 for Windows with a $95 \%$ confidence level. $\mathrm{p} \geq 0.05$ was considered statistically insignificant, while $\mathrm{p}<0.05$ was considered statistically significant.

\section{Results}

Fifty patients (34 men and 16 women) were enrolled in our study. The median age was $56.64 \pm 18$ years ( 17 to 83 years of age). The results of compared groups are showed in Table 1 .

Age: the cases were divided into two groups, over 45 years and 45 or under. There was no significant difference in CRBSI $(p=0.889$ and $p>0.05)$ or $C C(p=0.891$ and $p>0.05)$ between the two age groups.

Gender: The cases were divided into two groups according to gender. There was no significant difference in CRBSI $(p=0.064$ and $p>0.05)$ or $C C(p=0.064$ and $p>0.05)$ based on gender.

Presence of Malignancy: Cases were divided into two groups based on the presence or absence of malignancy. There was no 
$548-551$

significant difference in CRBSI $(\mathrm{p}=0.103$ and $\mathrm{p}>0.05)$ or $\mathrm{CC}(\mathrm{p}$ $=0.409$ and $\mathrm{p}>0.05$ ) between the two groups.

Presence of Coexisting Disease: Cases with and without coexisting disease were divided into two groups. There was no significant difference in CRBSI $(\mathrm{p}=0.606$ and $\mathrm{p}>0.05)$ or $\mathrm{CC}(\mathrm{p}=$ 0.280 and $p>0.05$ ) between the two groups.

Number of Coexisting Diseases: Cases were divided into three groups based on whether there was zero, one, or more than one coexisting disease. There was no significant difference in CRBSI $(\mathrm{p}=0.525$ and $\mathrm{p}>0.05$, Table 10 , Chart 9$)$ or $\mathrm{CC}(\mathrm{p}=0.557$ and $\mathrm{p}$ $>0.05$ ) among the three groups.

Catheter Duration: Cases were divided into two groups, those with catheters for less than seven days and those with catheters for seven or more days. There was no significant difference in CRBSI ( $p=0.867$ and $\mathrm{p}>0.05)$ or $\mathrm{CC}(\mathrm{p}=0.239$ and $\mathrm{p}>0.05)$ based on catheterduration.

Use of TPN solution: Cases were divided into two groups according to whether or not they received TPN solution. There was no significant difference in CRBSI $(\mathrm{p}=0.543$ and $\mathrm{p}>0.05)$ or CC $(p=0.304$ and $p>0.05)$ between the two groups.

Blood Product Usage: Cases were divided into two groups according to whether or not they received blood products. There was no significant difference in CRBSI $(p=0.260$ and $p>0.05)$ or $\mathrm{CC}(\mathrm{p}=0.266$ and $\mathrm{p}>0.05)$ between the two groups.

Antibiotic Use: Cases were divided into two groups according to whether or not they received antibiotics. There was no significant difference in CRBSI $(p=0.567$ and $p>0.05)$ or CC $(p=0.561$ and $\mathrm{p}>0.05$ ) between the two groups.

Use of the Skin Antiseptics Chlorhexidine or Povidone-Iodine: Cases were divided into two groups according to which antiseptic were used. There was a significant difference in CRBSI ( $p=$ 0.022 and $\mathrm{p}<0.05)$ and $\mathrm{CC}(\mathrm{p}=0.047$ and $\mathrm{p}<0.05)$ between the two antiseptics.

\section{Discussion}

The use of central venous catheters is gradually becoming more prevalent. While the actual number of catheters used in our own country is unknown, in the United States, the annual number approximates 5 million (8). Nevertheless, the use of a CVC can have negative side effects that are difficult to treat. CRBSI, being the most frequent, results in patient morbidity and even mortality. CRBSI develops in approximately 3 to $8 \%$ of all catheter procedures, mostly caused by nosocomial bacteria. This situation equates with approximately $\$ 30,000$ per patient in additional costs and two to three more weeks at hospital (9). In the development of CRBSI and CC, the patient's age and gender, catheter duration, presence of malignancy or comorbid disease, use of TPN, blood products, antibiotics, and catheter location, as well as the use of skin antiseptics and antibacterial catheters have been thought to have an influence, and much research has been conducted on the subject. In all of the studies carried out, age, sex, malignancies, presence of coexisting diseases, and the use of antibiotics were shown to have significant effect on the development of infections (10). In our study these factors were found to be insignificant in the development of infection.
In some studies it has been reported that catheters used for TPN have a higher risk of infection (11). However, Young et al found that when they had patients randomly take only TPN solution from single- or multiple-lumens, the single-lumen catheter infection rate was significantly lower (12). Dimick et al determined that bacteria colonization rates decreased by a factor of five with a single-lumen subclavian catheter used solely for TPN solution (13). In our study, the use of TPN did not have a statistically significant effect on CRBSI or CC ( $\mathrm{p}=0.543$ or $\mathrm{p}=0.304$, respectively).

Moro et al determined that catheter colonization increased with extended catheter duration (14). In their study, Cook et al showed that there is no advantage to changing catheters on a 7 to 10 day plan in terms of clinical indications (15). In our study, we found no significant difference in CRBSI or CC between patients whose catheters remained in place for less than seven days and those whose catheters remained for seven days or more $(\mathrm{p}=0.867$ or $\mathrm{p}=0.239$, respectively).

In terms of preventing CRBSI, measures should be adopted to take maximum care in disinfecting the catheter (16) as well as disinfecting the area where the catheter is placed with antiseptic solutions. However, there is currently no consensus on which antiseptic solution is best. In our study, we investigated the effects of using aqueous chlorhexidine and povidone-iodine solutions for skin disinfection on CRBSI and CC. In most of the trials carried out, chlorhexidine solutions were more effective than aqueous povidone iodine solutions in reducing the risk of CC $(17,18)$ and CRBSI (19). This success of chlorhexidine solutions can be explained by some properties of these solutions. Topically applied chlorhexidine solutions are poorly absorbed by the skin and do not have any systemic toxic effects. After its application, the residual antimicrobial effects last longer than those of povidoneiodine $(10,20)$. Moreover, chlorhexidine gluconate is a cationic biguanide with a broad spectrum of antimicrobial effect and when combined with alcohol it could be most effective against pathogenic microorganisms, reduce CRSBI and allow extended catheter durations. Chlorhexidine has not been reported to have any drug interactions $(21,22)$. In contrast, many compounds in the body can deactivate povidone-iodine. Chlorhexidine gluconate does not result in greater bacterial resistance.

Of the many factors in our study, only the use of chlorhexidine over povidone-iodine as a skin antiseptic had any statistically significant effect on decreasing CRBSI and CC ( $p=0.022$ and $p=0.047$, respectively). In a study comparing solutions of chlorhexidine based on water to those based on alcohol, it was shown that they are similarly effective and both more effective than povidone-iodine (23).

Similar successful results have been obtained with the use of chlorhexidine-containing bandages. In a study carried out by Ruschulte et al, the use of chlorhexidine-containing bandages significantly decreased the incidence CRBSI in patients receiving chemotherapy (24). These findings are supported by Eggimann's review (25). Borschel et al have proven that the use of central venous catheters coated with chlorhexidine/silver-sulfadiazene has positive clinical and economic effects (26). The same positive effect has not been obtained with antibiotic-using catheters (27). 
Our study concludes that skin antisepsis is the only determining factor in the prevention of blood infection and colonization due to central venous catheter application while the use of clorhexidine vs povidon is proven to be statistically significant.

\section{References}

1. Henderson DK. Infections caused by percutaneoeus intravascular devices. In: Mandeli GL, Bennett JE, Dolin R (Eds). Principles and Practice of Infectious Diseases. 6th ed. Philadelphia: Churchill-Livingstone Inc, $2005,3347-3362$.

2. O'Grady NP, Alexander M, Dellinger EP, Gerberding JL, Heard So, Maki DG, Masur H, McCormick RD, Mermel LA, Pearson ML, Raal II, Randolph A, Weinstein RA. Guidelines for the prevention of intravascular catheter-related infections. MMWR Recomm Rep 2002; 51(RR-10): $1-29$.

3. Seifert H, Jansen B, Widmer AF, Farr BM. Central venous catheters. In: Seifert H, Jansen B, Farr BM (eds). Catheter- Related Infections. 2th ed. New York: Marcel Dekker, 2005, 293 - 326.

4. Polderman KH, Girbes ARJ. Central venous catheter use. Part 1. Mechanical complications. Intensive Care MEd 2002; 28: 1 - 17.

5. Polderman KH, Girbes ARJ. Central venous catheter use. Part 2. Infectious complications. Intensive Care Med 2002; 28: 18 - 28.

6. Mermel LA, Farr BM, Sherertz RJ, Raad II, O'Grady N, Haris JS, Craven DE, Guidelines for the management of intravascular catheterrelated infections. Clin Infect Dis 2001; 32: 1249 - 1272.

7. Afif C, Raad II. Intravascular catheter- related infections. In: Schlossberg D (ed). Current Therapy of Infectious Disease. 2nd. Ed. St. Louis: Mosby, 2001, 416- 418 .

8. Raad I. Intravascular-catheter-related infections. Lancet 1998; 351 (9106): $893-898$.

9. Pittet D, Tarara D, Wenzel RP. Nosocomial bloodstream infection in critically ill patients: excess length of stay, extra costs, and attributable mortality JAMA 1994; 271 (20): 1598 - 1601.

10. Olivier Mimoz, MD, PhD et al. Chlorhexidine-based antiseptik solution vs alcohol-based povidone-iodine for central venous catheter care. Arcch Intern Med 2007; 167 (19): 2066 - 2072.

11. Moro ML, Vigano EF, Cozzi A. Risk factors for central venous catheter related infections in surgical and intensive care units. The Central Venous Catheter Related Infections Study Group. Infect Control Hosp Epidemiol 1994; 15: 254 - 264.

12. Yeung C, May J, Hughes R. Infection rate for single vs tripl lumen subclavian catheters. Infect Control Hosp Epidemiol 1998; 9: 154 - 158.

13. Dimick JB, Swoboda S, Talamini MA, Pelz RK, Hendrix CW, Lipsett PA. Risk of colonization of central venous catheters: catheters for total parenteral nutrition vs other catheters. Am J Crit Care 2003; 12: 328 - 335.
14. Tacconelli E, Tumbarello M, Pittiruti M et al. Central venous catheter related sepsis in a cohort of 386 hospitalized patients. Eur J Clin Microbiol Dis 1997; 16: $203-209$.

15. Cook D, Randolph A, et al Central venous cathater replacement strategies: a systematic review of the literature. Crit Care Med 1997; 25: 1417 $-1424$.

16. O'Grady NP, Alexander M, Dellinger EP et al Centers for Disease Control and Prevention. Guidelines for the prevention of intravascular catheter-related infections. MMWR Recomm Rep 2002; 51(RR-10)(RR10): $1-29$.

17. Maki DG, Ringer M, Alvarado CJ. Prospective randomised trial of povidone-iodine, alcohol, and chlorhexidine for prevention of infection associated with central venous and arterial catheters. Lancet 1991; 338 (8763): $339-343$.

18. Mimoz O, Pieroni L, Lawrence $C$ et al. Prospective, randomized trial of two antiseptic solutions for prevention of central venous or arterial catheter colonization and infection in intensive care unit patients. Crit Care Med 1996; 24 (11): 1818 - 1823.

19. Chaiyakunapruk N, Veenstra DL, Lipsky BA, Saint S. Chlorhexidine compared with povidone-iodine solution for vascular catheter-site care: a meta-analysis. Ann Intern Med 2002; 136 (11): 792 - 801.

20. Lim KS, Kam PC. Chlorhexidine pharmacology and clinical applications. Depart of Anaesthetics, University of Sidney, Royal Prince Alred Hospital, Sydney, New South Wales, Australia. Anaesth Intensive Care 2008; 36 (4): $502-512$.

21. Zamora JL, Price MF, Chuang P, Gentry LO. Inhibition of povidone-iodine's bactericidal activity by common organic substances: an experimental study. Surgery 1985; 98: $25-29$.

22. Lowbury EJ, Lilly HA. The effect of blood on disinfection of surgeons' hands. Br J Surg 1974; 61: 19 - 21.

23. Valles J, Fernandez I, Alcaraz D et al. Prospective randomized trial of 3 antiseptic solutions for prevention of catheter colonization in an intensive care unit for adult patients. Infect Control Hosp Epidemiol 2008; 29 (9): $847-853$.

24. Ruschulte H, Franke M, Gastmeier P et al. Prevention of central venous catheter related infections with chlorhexidine gluconate impregnated wound dressings: a randomized controlled trial. Ann Hematol 2009; 88 (3): $267-272$.

25. Eggimann P. Prevention of intravascular catheter infections. Curr Opin Infect Dis 2007; 20 (4): 360 - 369.

26. Borschel DM, Chenoweth CE, Kaufman SR et al. Are antisepticcoated central venous catheters effective in a real-world setting? Ann Arbor 48109 - 0376, USA.

27. Halton KA, Cook DA, Whitby M et al. Cost-effectiveness of antimicrobial catheters in the intensive care unit: addressing uncertainty in the decision. Crit Care 2009; 13 (2): R35. 